\title{
Publisher Correction: Discordant congenital Zika syndrome twins show differential in vitro viral susceptibility of neural progenitor cells
}

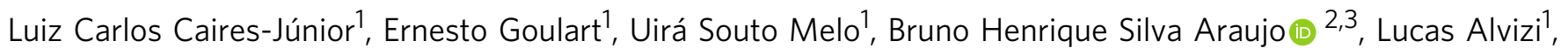
Alessandra Soares-Schanoski ${ }^{4}$, Danyllo Felipe de Oliveira', Gerson Shigeru Kobayashi', Karina Griesi-Oliveira ${ }^{1,5}$, Camila Manso Musso', Murilo Sena Amaral', Lucas Ferreira daSilva ${ }^{6}$, Renato Mancini Astray ${ }^{4}$,

Sandra Fernanda Suárez-Patiño ${ }^{4}$, Daniella Cristina Ventini ${ }^{4}$, Sérgio Gomes da Silva ${ }^{5,7}$,

Guilherme Lopes Yamamoto', Suzana Ezquina ${ }^{1}$, Michel Satya Naslavsky', Kayque Alves Telles-Silva', Karina Weinmann", Vanessa van der Linden ${ }^{8}$, Helio van der Linden ${ }^{9}$, João Ricardo Mendes de Oliveira ${ }^{10}$, Nivia Maria Rodrigues Arrais ${ }^{11}$, Adriana Melo ${ }^{12}$, Thalita Figueiredo ${ }^{1}$, Silvana Santos ${ }^{13}$, Joanna Goes Castro Meira ${ }^{14}$, Saulo Duarte Passos ${ }^{15}$, Roque Pacheco de Almeida ${ }^{16}$, Ana Jovina Barreto Bispo ${ }^{16}$, Esper Abrão Cavalheiro ${ }^{3}$, Jorge Kalil ${ }^{4}$, Edécio Cunha-Neto ${ }^{17}$, Helder Nakaya (1) ${ }^{18}$, Robert Andreata-Santos ${ }^{19}$, Luis Carlos de Souza Ferreira ${ }^{19}$, Sergio Verjovski-Almeida (ib) ${ }^{4,6}$, Paulo Lee Ho ${ }^{4}$, Maria Rita Passos-Bueno ${ }^{1} \&$ Mayana Zatz ${ }^{1}$

Correction to: Nature Communications https://doi.org/10.1038/s41467-017-02790-9; published online 02 February 2018

The original PDF version of this Article contained errors in the spelling of Luiz Carlos Caires-Júnior, Uirá Souto Melo, Bruno Henrique Silva Araujo, Alessandra Soares-Schanoski, Murilo Sena Amaral, Kayque Alves Telles-Silva, Vanessa van der Linden, Helio van der Linden, João Ricardo Mendes de Oliveira, Nivia Maria Rodrigues Arrais, Joanna Goes Castro Meira, Ana Jovina Barreto Bispo, Esper Abrão Cavalheiro, and Robert Andreata-Santos, which were incorrectly given as Luiz Carlos de Caires Jr., UiráSouto Melo, Bruno Silva Henrique Araujo, Alessandra Soares Schanoski, MuriloSena Amaral, Kayque Telles Alves Silva, Vanessa Van der Linden, Helio Van der Linden, João Mendes Ricardo de Oliveira, Nivia Rodrigues Maria Arrais, Joanna Castro Goes Meira, Ana JovinaBarreto Bispo, EsperAbrão Cavalheiro, and Robert Andreata Santos. Furthermore, in both the PDF and HTML versions of the Article, the top panel of Fig. 3e was incorrectly labeled '10608-1' and should have been '10608-4', and financial support from CAPES and DECIT-MS was inadvertently omitted from the Acknowledgements section. These errors have now been corrected in both the PDF and HTML versions of the Article.

\footnotetext{
${ }^{1}$ Department of Genetics and Evolutionary Biology, Human Genome and Stem Cell Research Center, Biosciences Institute, University of São Paulo (USP), São Paulo - SP 05508-900, Brazil. ${ }^{2}$ Brazilian Biosciences National Laboratory (LNBio), Brazilian Center for Research in Energy and Materials (CNPEM), Campinas - SP 13083-970, Brazil. ${ }^{3}$ Neuroscience laboratory, Department of Neurology and Neurosurgery, Federal University of São Paulo-UNIFESP/EPM, São Paulo - SP 04039-002, Brazil. ${ }^{4}$ Butantan Institute, São Paulo - SP 05503-900, Brazil. ${ }^{5}$ Albert Einstein Hospital, São Paulo - SP 05652-900, Brazil. ${ }^{6}$ Department of Biochemistry, Institute of Chemistry, University of São Paulo (USP), São Paulo - SP 05508-900, Brazil. ${ }^{7}$ Universidade de Mogi das Cruzes, Mogi das Cruzes - SP 08780-911, Brazil. ${ }^{8}$ AACD, Recife - PE 50080-810, Brazil. ${ }^{9}$ Rehabilitation Center-Dr. Henrique Santillo, Goiânia - GO 74653-230, Brazil. ${ }^{10}$ Neuropsychiatry Department and KeizoAsami Laboratory, Federal University of Pernambuco (UFPE), Recife - PE 50670-901, Brazil. ${ }^{11}$ Department of Pediatrics, Federal University of Rio Grande do Norte (UFRN), Natal- RN 59010-180, Brazil. ${ }^{12}$ ISEA, Campina Grande- PB 58400-220, Brazil. ${ }^{13}$ Department of Biology, Paraíba State University (UEPB), Campina Grande - PB 58429-500, Brazil. ${ }^{14}$ Federal University of Bahia (UFBA), Salvador - BA 40170-115, Brazil. 15 Infectious pediatric laboratory, Medicine School of Jundiaí, Jundiaí - SP 40170-115, Brazil. ${ }^{16}$ Division of Immunology and Molecular Biology Laboratory, Federal University of Sergipe (UFS), Aracaju - SP 49100-000, Brazil. ${ }^{17}$ Heart Institute, Faculty of Medicine, University of São Paulo (USP), São Paulo - SP 05403-900, Brazil. ${ }^{18}$ Department of Clinical and Toxicological Analyses, School of Pharmaceutical Sciences, University of São Paulo (USP), São Paulo - SP 05508-900, Brazil. ${ }^{19}$ Vaccine Development Laboratory, Department of Microbiology, Institute of Biomedical Science, University of São Paulo (USP), São Paulo - SP 05508-900, Brazil. Correspondence and requests for materials should be addressed to M.Z. (email: mayazatz@usp.br)
} 
Published online: 13 March 2018

(c) Open Access This article is licensed under a Creative Commons Attribution 4.0 International License, which permits use, sharing, adaptation, distribution and Ceproduction in any medium or format, as long as you give appropriate credit to the original author(s) and the source, provide a link to the Creative Commons license, and indicate if changes were made. The images or other third party material in this article are included in the article's Creative Commons license, unless indicated otherwise in a credit line to the material. If material is not included in the article's Creative Commons license and your intended use is not permitted by statutory regulation or exceeds the permitted use, you will need to obtain permission directly from the copyright holder. To view a copy of this license, visit http://creativecommons.org/licenses/by/4.0/.

(C) The Author(s) 2018 